\title{
GTn Repeat Microsatellite Instability in Uterine Fibroids
}

\author{
Bineta Kénémé ${ }^{1 *}$ and Mbacké Sembène ${ }^{1,2}$ \\ ${ }^{1}$ GenGesPop, Cheikh Anta Diop University, Animal Biology, Dakar-Fann, Senegal, ${ }^{2}$ Biopass, IRD, Dakar-Bel Air, Senegal
}

\section{OPEN ACCESS}

Edited by:

Barbara Karen Dunn, National Institutes of Health $(\mathrm{N} / \mathrm{H})$,

United States

Reviewed by:

Pawel Buczkowicz,

Gene42, Inc., Canada Jun Zhong, National Cancer Institute (NCl), United States

*Correspondence:

Bineta Keneme bineta.keneme@ucad.edu.sn

Specialty section:

This article was submitted to

Cancer Genetics,

a section of the journal

Frontiers in Genetics

Received: 28 January 2019

Accepted: 02 August 2019

Published: 20 September 2019

Citation:

Kénémé B and Sembène M (2019) GTn Repeat Microsatellite Instability in Uterine Fibroids.

Front. Genet. 10:810.

doi: 10.3389/fgene.2019.00810
Background: Type / collagen is a triple helix structure with two $\alpha 1$ and one $\alpha 2$ chains. Coordinated biosynthesis of $\alpha 1$ and $\alpha 2$ subunits is very important for tissue morphogenesis, growth, and repair. In contrast, abnormal deposition in response to proinflammatory cytokines is associated with organ dysfunction. In humans, COL1A2 contains two microsatellite loci: one located at the 5'-flanking region is composed of poly CA and poly CG; the other located in the 1st intron is constituted of poly GT. Expression of COL1A2 has been noted in gastric cancer and was positively correlated with degree of invasion and metastases. But no genetic study taking into account polymorphism of COL1A2 in uterine fibroids has been undertaken.

Methods: In this study, repeated dinucleotide $\mathbf{G T}_{\mathbf{n}}$ of intron 1 COL1A2 was highlighted in 55 patients with uterine fibroids (UF). Clinical and pathological data were obtained from patient's records, and other parameters were recorded. Mutation Surveyor version 5.0.1, DnaSP version 5.10, MEGA version 7.0.26, and Arlequin version 3.5.1.3 were used to determine genetics parameters. To estimate genetic variation according to epidemiological parameters, index of genetic differentiation (Fst) and genetic structure (AMOVA) were determined with Arlequin version.

Results: Based on reference microsatellite pattern $(\mathbf{G T})_{14} \mathbf{C T}(\mathbf{G T})_{3} \mathbf{C T}(\mathbf{G T})_{3}, 15$ haplotypes were found. Among the 15 haplotypes, 12 have mutation at position $\mathbf{2 2 8 4 \mathbf { C }}>\mathbf{G}$ and 7 at position $\mathbf{2 2 9 2 C}>\mathbf{G}$. Insertions of repeated dinucleotide $\mathrm{GT}_{\mathrm{n}}$ were found on three haplotypes against eight haplotypes in which they are deletions. Intron 1 of COL1A2 gene exhibits high genetic diversity in uterine fibroids with $35.34 \%$ polymorphic sites, $95.74 \%$ of which were parsimoniously variable and an average number of nucleotide difference of 10.442, which reflects an important genetic variability. According to epidemiological parameters, our results showed, for the first time, a genetic structuring of uterine fibroids according to ethnicity, marital status, use of contraception, diet, and physical activity, beyond confirming the involvement dinucleotide length polymorphism $\mathrm{GT}_{\mathrm{n}}$ in occurrence of uterine fibroids in Senegalese women.

Conclusion: Results obtained open up avenues for understanding the mechanisms involved in the racial variation in the prevalence of uterine fibroids as well as the predisposing factors.

Keywords: uterine fibroid, COL1A2 polymorphism, risk factors, Senegal, microsatellite genetic marker 


\section{INTRODUCTION}

Uterine fibroids (UF), more commonly known as myomas or uterine leiomyomas, are the most common benign tumors of female reproductive organs. They are associated with significant morbidity and therefore constitute a real public health problem. UF, which are highly variable within uterus, develop at the expense of smooth muscle and are often separated from the myometrium by a pseudocapsule associated with connective tissue condensation (Audebert, 1990). Heterogeneity of UF localization and their progression in the same patient illustrate the complex biological mechanism involved in their development. Clinically, UF are firm, stiff nodular tumours, a fact confirmed by biomechanical studies. Proteins of extracellular matrix, especially interstitial collagens, are responsible for this property of "firmness" and mechanical strength of tissue. Indeed, UF have an accumulation of altered collagens and different amounts of glycosaminoglycans and a proliferation of cells, which is by definition a fibrosis. A complete understanding of the role of extracellular matrix proteins, in particular collagen, and their effect on the growth and development of UF becomes an important issue for elucidating molecular mechanisms involved in their etiology.

Located on chromosome 7, COL1A2 is an essential component of matrix tissue. It is predominantly produced by mesenchymal cells such as fibroblasts, osteoblasts, and smooth muscle cells. Transcription of COL1A2 is under control of a regulatory complex that includes several DNA elements and several trans-activating factors. During the last two decades, type I alpha chain collagen 2 (COL1A2) has been considered as an informative model for studying principles that govern the control of extracellular matrix transcription for normal and fibrotic tissues (Kirkland, 2009; Krasny et al., 2010; Trojonowska, 2002; Yasul et al., 2004). In humans, COL1A2 contains two microsatellite loci: one located at the 5'-flanking region of the gene is composed of poly CA and poly CG; the other located in the 1st intron is constituted of poly GT. In a study led by Akai et al. (1999), it has been shown that complete transcription of COL1A2 gene is regulated by these repeated dinucleotides. Analysis of polymorphism in these two regions indicates that these two sequences show a variation in their repetition number, suggesting that these dinucleotides constitute microsatellites. Lei et al. (2005) hypothesized that $\mathrm{GT}_{\mathrm{n}}$ polymorphism triggers transcription of the gene, and variation in the number of repetitions can partly be responsible for the difference in transcriptional activity. In this study, we evaluate instability of repeated dinucleotide $\mathbf{G T}_{\mathbf{n}}$ in Senegalese patients with UF.

\section{MATERIALS AND METHODS}

\section{Clinical Sampling}

Tumor tissue samples were collected from 55 patients with UF (from Military Hospital of Ouakam and General Hospital of Grand Yoff). Clinical and pathological data were recorded including age, ethnicity, age at menarche, marital status, number of pregnancies, number of childbirth, hormonal contraception, diet, and physical activity (Table 1). None of the patients surveyed claimed to consuming alcohol and using tobacco, which is why these factors are not included in this study.

\section{DNA Extraction, Amplification, and Sequencing of Intron 1 COL1A2 Gene}

Total DNA of each sample was extracted using Qiagen protocol (Qiagen Dneasy Tissue kit). After extraction, repeated dinucleotide $\mathbf{G T}_{\mathbf{n}}$ were amplified using forward 5'-TGTCT ACCACTGCATAATTTC-3 and reverse 5'-AATATGAACTCG GTAATGTGA-3' primers (Lei et al., 2005). The 35 cycle PCR for COL1A2 intron 1 amplification was carried out using $4 \mu \mathrm{l}$ of human genomic DNA in a $50 \mu$ l reaction mixture, which contained $0.1 \mu \mathrm{l}$ of Taq DNA polymerase, $2.5 \mu \mathrm{l}$ of forward and reverse primers, $1 \mu \mathrm{l}$ of magnesium chloride, $2 \mu \mathrm{l}$ of mix dNTPs, and $5 \mu \mathrm{l}$ of $10 \mathrm{X}$ ammonium sulfate buffer. Thermal cycle conditions for amplification PCR consisted of 1st step-3 min

TABLE 1 | Clinical and pathological characteristics of 55 cases analyzed.

Epidemiological factors

Number of patients (\%)

Age $(n=36)$

$\leq 35$

]35-45]

$>45$

Ethnicity $(n=39)$

Wolof

Sérère

Lébou

Bambara

Diola

Alpulaar

Marital status $(n=31)$

Single

Married

Divorced

Age at menarche $(n=18)$

$\leq 12$

]12-15]

$>15$

Number of pregnancies $(n=31)$

0

I

III

III

Number of childbirth $(n=33)$

0

I

II

III

$>$ III

Hormonal contraception $(n=23)$

Yes

No

Diet $(\mathbf{n}=\mathbf{2 3})$

Meat preference

Vegetarian preference

No preference

Physical activity $(n=23)$

Yes

No
$11(30.55 \%)$

$18(50 \%)$

$7(19.45 \%)$

$13(33.33 \%)$

$4(10.26 \%)$

$7(17.95 \%)$

$3(7.69 \%)$

$5(12.82 \%)$

$7(17.95 \%)$

$8(25.80 \%)$

$20(64.52 \%)$

$3(9.68 \%)$

$1(5.56 \%)$

$13(72.22 \%)$

$4(22.22 \%)$

$20(64.51 \%)$

$4(12.91 \%)$

$4(12.91 \%)$

$1(3.22 \%)$

$2(6.45 \%)$

$23(69.70 \%)$

$7(21.21 \%)$

$1(3.03 \%)$

$2(6.06 \%)$

$0(0 \%)$

$2(8.69 \%)$

$21(91.31)$

$7(30.43 \%)$

$6(26.09 \%)$

$10(43.48 \%)$

$5(21.74 \%)$

$18(78.26 \%)$ 
cycle of initial denaturation at a temperature of $94^{\circ} \mathrm{C}$, followed by 2 nd step consisting of 35 cycles each of $45 \mathrm{~s}$ of denaturation at $94^{\circ} \mathrm{C}$, annealing at $60^{\circ} \mathrm{C} / 1 \mathrm{~min}$ and primer extension at $72^{\circ} \mathrm{C} / 1 \mathrm{~min}$, and $3 \mathrm{rd}$ step: final extension or polymerization at $72^{\circ} \mathrm{C}$ for $10 \mathrm{~min}$. After PCR reaction, all products were electrophoresed on $1.5 \%$ agarose gel, followed by its analysis in an UVitec Gel Documentation system for imaging the gel and to determine the amplicon lengths. Sequencing reactions were performed in a thermal cycler MJ Research PTC-225 Peltier type with ABI PRISM BigDye TM Terminator Cycle kit. Each sample was sequenced using forward primer. Fluorescent fragments were purified with the BigDye Xterminator purification protocol. The samples were suspended in distilled water and subjected to electrophoresis in 3730xl ABI sequencer (Applied Biosystems).

\section{Molecular Analysis}

To determine length polymorphism of dinucleotide $\mathbf{G T}_{\mathbf{n}}$ of intron 1 COL1A2 gene, the raw sequencing data were submitted to Mutation Surveyor software version 5.0.1 (www.softgenetics.com). This program can directly compare chromatograms with genomic DNA of reference sequence of COL1A2 (NT_007933_94023373). Alignment of the sequences was carried out using BioEdit software version 8.0.5 and ClustalW algorithm (Thompson et al., 1994). Sequences obtained (Hall, 1999) were thoroughly checked, cleaned, and aligned to identify homologies among sites, and also to perform other phylogenetic analysis including the determination of variability index and genetic diversity as well as the parameters of genetic differentiation. Genetic variability parameters (number of polymorphic sites, total number of haplotype, average number of nucleotide difference $\mathrm{K}$ ) were obtained through DnaSP 5.10 software (Librado and Rozas, 2009) and MEGA 7.0.26 (Kumar et al., 2016). To estimate genetic variation according to epidemiological parameters, the factor of genetic differentiation (Fst) and the analysis of molecular variance (AMOVA) were determined with Arlequin software version 3.5.1.3 (Excoffier and Lischer, 2010). Values of P less than 0.05 are considered significant at a $5 \%$ confidence interval.

\section{RESULTS}

\section{Mutations Status of Microsatellite $\mathbf{G T}_{\mathrm{n}}$}

COL1A2 was sequenced in 55 tumour tissues. Of these sequences, five were removed from the genetic analysis because of a strong polymorphism. Based on the microsatellite reference pattern in the form $(\mathrm{GT})_{14} \mathrm{CT}(\mathrm{GT})_{3} \mathrm{CT}(\mathrm{GT})_{3}, 15$ haplotypes were found in 50 Senegalese women with UF (Table 2). These haplotypes indicate a variation in GT repetition number ranging from 13 to 25 (Figure 1).

Of the 15 haplotypes, 12 have mutation at position $2284 \mathrm{C}>$ G (first site that interrupts GT dinucleotide repeat) and 7 have mutation at $2292 \mathrm{C}>\mathbf{G}$ (2nd site that interrupts GT dinucleotide repeat). Insertions of repeated dinucleotide $\mathrm{GT}_{\mathrm{n}}$ were found on three haplotypes (microsatellite elongation) compared to eight haplotypes in which they were deletions (microsatellite shortening). Haplotype 7 representing $20 \%$ of the haplotypes was characterized by the presence of two types of transversions $2284 \mathrm{C}>\mathrm{G}$ and $2292 \mathrm{C}>\mathrm{G}$. Haplotypes $11(14 \%)$ and $8(12 \%)$ were respectively characterized by deletions at position 2280-2283_DelGTGT and 2282-2283 DelGT (Table 2). Some microsatellite length polymorphisms of $\mathbf{G T}_{\mathbf{n}}$ COL1A2 were summarized in Figure 2.

\section{COL1A2 Intron 1 Polymorphisms}

Intron 1 of $C O L 1 A 2$ gene exhibits high genetic diversity in UF with $35.34 \%$ polymorphic sites, $95.74 \%$ of which were parsimoniously variable. Average number of nucleotide differences was 10.442 (Table 3). The high haplotypic diversity $(\mathrm{Hd}=0.9984)$ and the low nucleotide diversity $(\mathrm{Pi}=0.0877)$ showed a rapid evolution of microsatellite polymorphism in UF in Senegalese women.

\section{Microsatellite $\mathbf{G T}_{\mathrm{n}}$ Instability and Genetic Differentiation}

Depending on epidemiological parameters studied, only repeated dinucleotide is taken into account in analysis. This allows us to highlight the role of the length polymorphism of intron 1 COL1A2. Results obtained show a variable expressivity of dinucleotide $\mathrm{GT}_{\mathrm{n}}$ in

TABLE 2 | Length and pattern polymorphism of repeated dinucleotide $\mathrm{GT}_{\mathrm{n}}$ of intron 1 COL1A2 gene in uterine fibroids.

\begin{tabular}{|c|c|c|c|}
\hline Haplotype & Number (\%) & Microsatellite pattern & Variants \\
\hline H1 & $5(10 \%)$ & $(\mathrm{GT})_{14} \mathrm{CT}(\mathrm{GT})_{3} \mathrm{CT}(\mathrm{GT})_{3}$ & Wide type \\
\hline $\mathrm{H} 2$ & $4(8 \%)$ & $(\mathrm{GT})_{17} \mathrm{CT}(\mathrm{GT})_{3} \mathrm{CT}(\mathrm{GT})_{3}$ & 2276_2281_InsGTGTGT \\
\hline H3 & $2(4 \%)$ & $\mathrm{GT}_{25}$ & 2276_2281_InsGTGTGT; 2284C > G; 2292C > G \\
\hline H4 & $1(2 \%)$ & $(\mathrm{GT})_{21} \mathrm{CT}(\mathrm{GT})_{3}$ & 2276_2281_InsGTGTGT; 2284C > G \\
\hline H5 & $2(4 \%)$ & $\mathrm{GT}_{23}$ & 2281-2282_InsGT; 2284C > G; 2292C > G \\
\hline H6 & $2(4 \%)$ & $(\mathrm{GT})_{18} \mathrm{CT}(\mathrm{GT})_{3}$ & $2284 C>G$ \\
\hline H7 & $10(20 \%)$ & $\mathrm{GT}_{22}$ & $2284 \mathrm{C}>\mathrm{G} ; 2292 \mathrm{C}>\mathrm{G}$ \\
\hline H8 & $6(12 \%)$ & $\left(\mathrm{GT}_{21}\right)$ & 2282-2283_DelGT; 2284C > G; 2292C > G \\
\hline H9 & $2(4 \%)$ & $(\mathrm{GT})_{13} \mathrm{CT}(\mathrm{GT})_{3} \mathrm{CT}(\mathrm{GT})_{3}$ & 2282-2283_DelGT \\
\hline H10 & $1(2 \%)$ & $(\mathrm{GT})_{17} \mathrm{CT}(\mathrm{GT})_{3}$ & 2282-2283_DelGT; 2284C > G \\
\hline H11 & $7(14 \%)$ & $(\mathrm{GT})_{16} \mathrm{CT}(\mathrm{GT})_{3}$ & 2280-2283_DelGTGT; 2284C > G \\
\hline H12 & $4(8 \%)$ & $\mathrm{GT}_{20}$ & 2280-2283_DelGTGT; 2284C > G; 2292C > G \\
\hline H13 & $1(2 \%)$ & $\mathrm{GT}_{19}$ & 2276-2281_DelGTGTGT; 2284C > G; 2292C > G \\
\hline H14 & $2(4 \%)$ & $(\mathrm{GT})_{15} \mathrm{CT}(\mathrm{GT})_{3}$ & 2276-2281_DelGTGTGT; 2284C > G \\
\hline H15 & $1(2 \%)$ & $\mathrm{GT}_{18}$ & 2274-2281_DelGTGTGTGT; 2284C > G; 2292C > G \\
\hline
\end{tabular}

Ins, insertion; Del, deletion. 


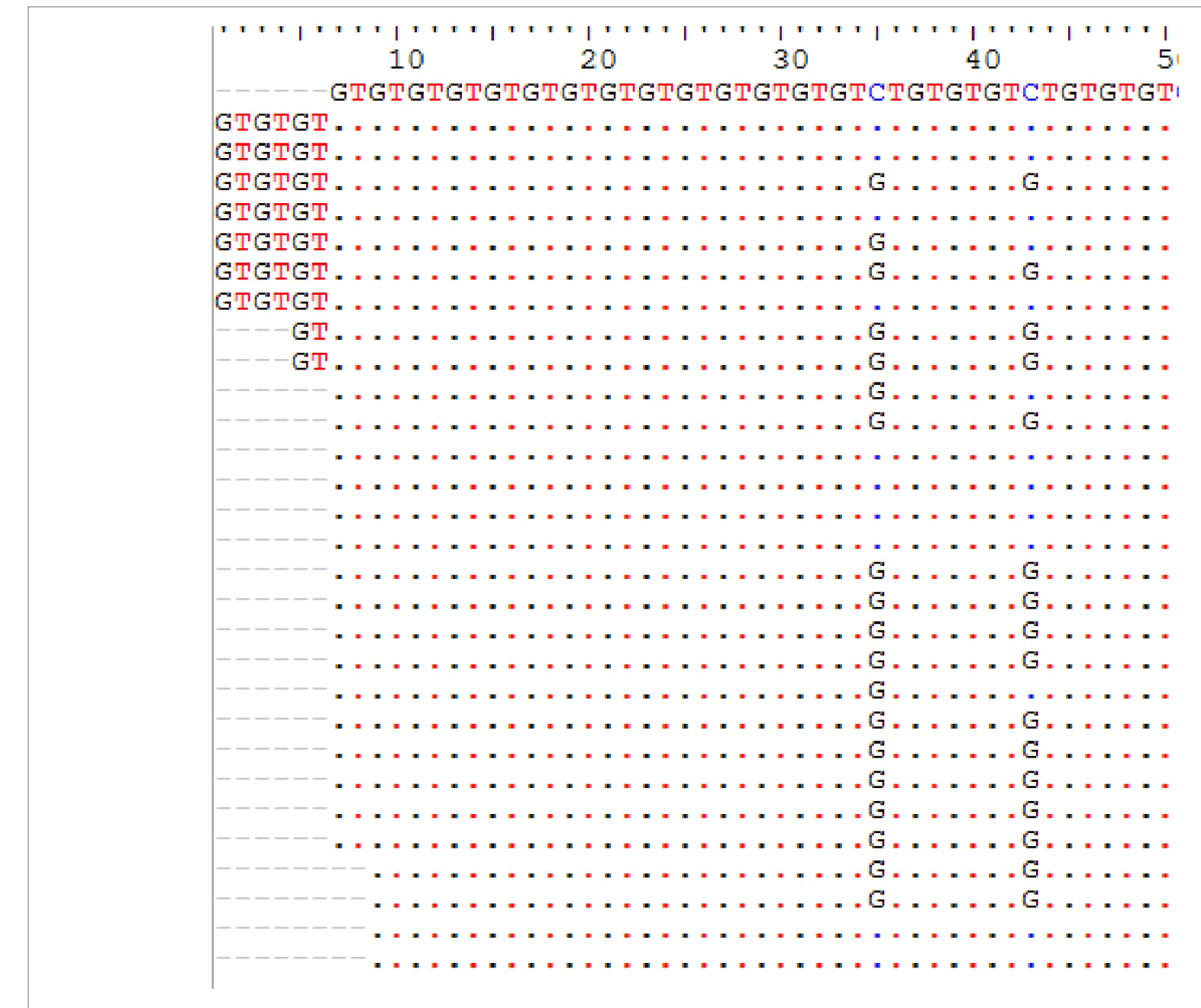

FIGURE 1 | Microsatellite $\mathrm{GT}_{\mathrm{n}}$ length and pattern polymorphism in uterine fibroids.

Senegalese women with UF (Table 4). For age parameter, tumoral tissues were genetically more different in women under 35 (Fst = $0.04237)$ and those over $45(\mathrm{Fst}=0.06574)$ compared to women aged 35-45 years (Fst $=0.03152$ ). This differentiation is more significant between the two extremes (under 35 and over 45). This heterogeneity of repeated dinucleotide $\mathrm{GT}_{\mathrm{n}}$ polymorphism is more noticeable among women of Bambara, Sérère, Lébou and Alpulaar ethnic groups, UF being genetically homogeneous in Wolof and Diola women. Strong genetic differentiation was noted between Wolof and Alpulaar.

According to marital status, UF seem to have the same genetic characteristics in single women $(\mathrm{Fst}=0.08964)$, unlike married women $(F s t=0.10771)$ and divorced women $(F s t=0.23556)$, where there is a strong genetic differentiation within each group. However, no statistically significant differentiation is noted between these groups.

For the age at menarche variable, only one woman who reported having menarche before the age of 12 had a different haplotype than the remaining 17 women on which age of menarche data was available. Further investigation with a larger patient cohort is required to determine the significance of this observation. As for the number of pregnancies, no statistically significant differentiation is noted between the sub-groups, but nevertheless, we notice a strong genetic differentiation in three women with three and more than three pregnancies. It is the same for the number of childbirth. Compared to hormonal contraception on the one hand and physical activity on the other hand, we noted an important genetic differentiation between sub-groups.

Polymorphism of repeated dinucleotide $\mathrm{GT}_{\mathrm{n}}$ was genetically different within women who have a meat preference and those who have no food preference. Women who are preferably vegetarians were genetically homogeneous (Table 4).

\section{Microsatellite $\mathbf{G T}_{\mathrm{n}}$ Instability and Molecular Variance Analysis}

The Fst values are further explained by molecular variance analysis (Table 5). Repeated dinucleotide $\mathrm{GT}_{\mathrm{n}}$ analysis showed that UF are genetically structured according to ethnicity $\left(\mathrm{p}=0.03421^{\star}\right)$, marital status $\left(\mathrm{p}=0.00782^{\star *}\right)$, hormonal contraception $(\mathrm{p}=$ $\left.0.00098^{\star * *}\right)$, dietary preference $\left(\mathrm{p}=0.04301^{\star}\right)$, and physical activity $\left(\mathrm{p}=0.00684^{* * *}\right)$. In other words, molecular mechanisms of COL1A2 involved in etiology of UF in Senegalese women 


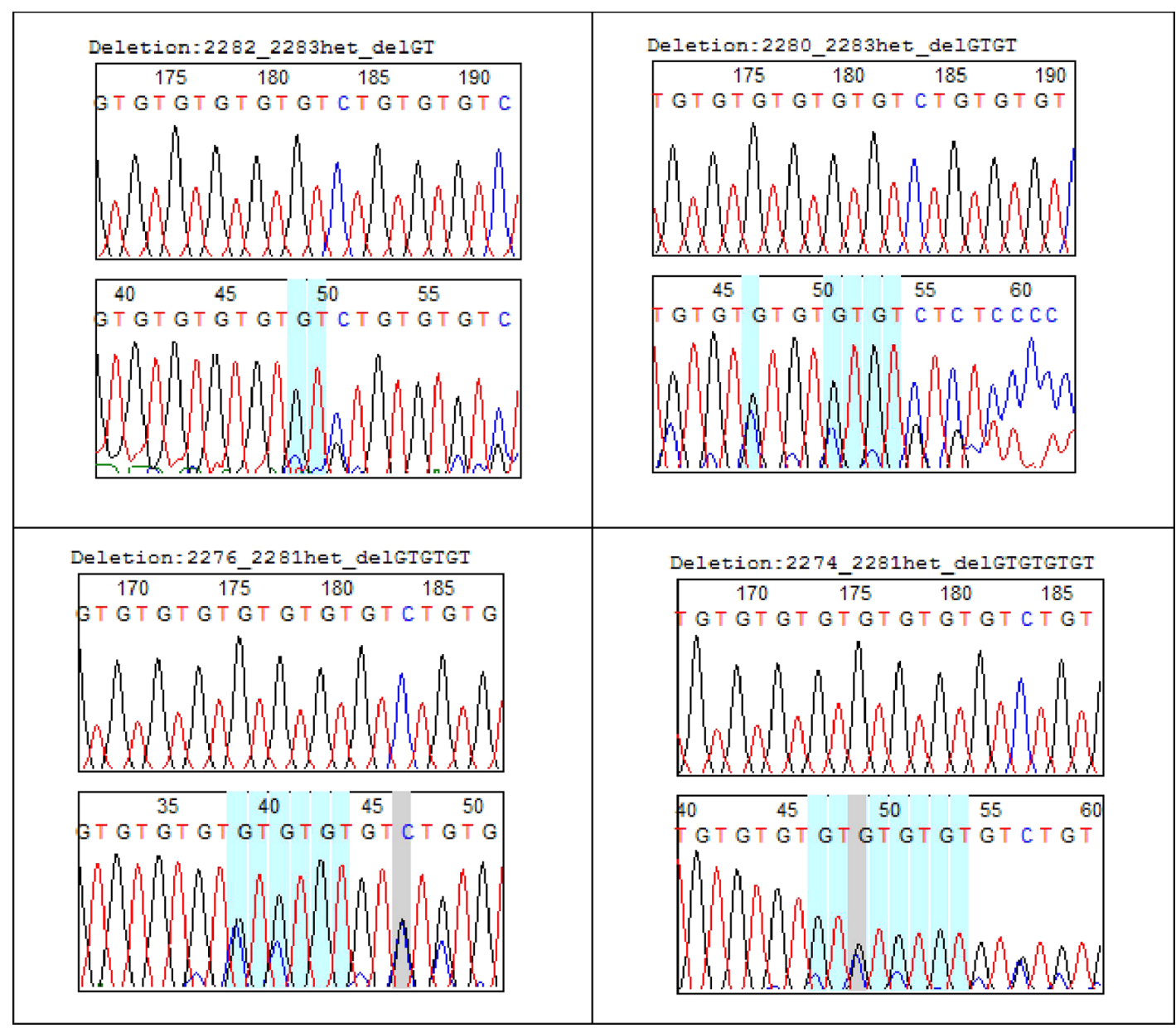

FIGURE 2 | $\mathrm{GT}_{\mathrm{n}}$ COLLA2 deletion in uterine fibroids.

TABLE 3 | Index of variability and genetic diversity of intron 1 COL1A2 in fibroid cases.

\begin{tabular}{lcc}
\hline \multicolumn{3}{c}{ Variability index } \\
\hline Parameters & Number & Percentage \\
\hline Number of sequences & 50 & \\
Number of sites & 133 & \\
Monomorphic sites & 86 & $64.66 \%$ \\
Polymorphic sites & 47 & $35.34 \%$ \\
Singleton variable sites & 2 & $4.26 \%$ \\
Parsimony informative sites & 45 & $95.74 \%$ \\
Average number of nucleotide & 10.442 & \\
differences (k) & & \\
& Genetic diversity index & \\
\hline Pi \pm variance & $0.0877 \pm 0.00002$ & \\
Hd \pm variance & $0.9984 \pm 0.00003$ & \\
\hline
\end{tabular}

Hd, haplotypic diversity; Pi, nucleotide diversity.

are modulated by risk factors such as ethnicity, marital status, hormonal contraception, diet, and physical activity. Indeed, the polymorphism of the repeated dinucleotide $\mathrm{GT}_{\mathrm{n}}$ of intron 1 COL1A2 in UF is explained to:
- $8.83 \%$ by differentiation between women of different ethnic groups;

- $10.57 \%$ by a differentiation between women according to their marital status;

- $24.88 \%$ by differentiation according to whether or not use of hormonal contraception;

- $7.94 \%$ by dietary preference; and

- $15.10 \%$ by a differentiation according to physical activity.

Since there is no multivariate analysis and the sample sizes are small for some of these variables, more research is needed to highlight these results.

\section{DISCUSSION}

\section{COL1A2 Polymorphisms in Uterine Fibroids}

Located on chromosome 7, COL1A2 is an essential component of the tissue matrix. It is predominantly produced by mesenchymal cells such as fibroblasts, osteoblasts, and smooth muscle cells (Rossert et al., 2000). Transcription of COL1A2 is under control 
TABLE 4 | Degree of genetic differentiation of repeated dinucleotide $\mathrm{GT}_{\mathrm{n}}$ of COL1A2 gene in relation to the epidemiological parameters studied.

Epidemiological parameters

Groups

Sub-groups

\section{Age}

$\leq 35$

]35-45]

$>45$

\section{Ethnicity}

Wolof

Sérère

Lébou

Bambara

Diola

Alpulaar
Genetic differentiation (Fst)
Within sub-groups
Between sub-groups

\section{Marital status}

Single

Married

0.08964

0.10771

0.23556

Age at menarche

$\leq 12$

0.20408

$-0.14031$

$-0.08291$

Number of pregnancies

0

I

III

$>$ III

\section{Number of childbirth}

0

I

II

III

Hormonal contraception

Yes

No

Diet

1 Meat preference

2 Vegetarian preference

3 No preference

0.00988

0.02840

$-0.11721$

0.34321

0.34321

\section{Physical activity}

Yes

No

$-0.06871$

$-0.13999$

0.26463

0.26463

0,17376

$-0,07280$

0.01042

$-0.01543$

0.01406

0.14435

0.07661

\section{Between sub-groups}

$\leq 35$ \&]35-45]

$\leq 35 \&>45$

]35-45] \& $>45$

Wolof \& Sérère

Wolof \& Lébou

Wolof \& Bambara

Wolof \& Diola

Wolof \& Alpulaar

Sérère \& Lébou

Sérère et Bambara

Sérère \& Diola

Sérère \& Alpulaar

Lébou \& Bambara

Lébou \& Diola

Lébou \& Alpulaar

Bambara \& Diola

Bambara \& Alpulaar

Diola \& Alpulaar

Single \& Married

Single \& Divorcée

Married \& Divorced

$$
\begin{gathered}
\leq 12 \&] 12-15] \\
\leq 12 \&>15 \\
\text { ] } 12-15] \&>15
\end{gathered}
$$

$$
\begin{gathered}
0 \& \mid \\
0 \&|| \\
0 \&|| \mid \\
0 \&>|| \mid \\
|\&| \mid \\
|\&||| \\
|\&>||| \\
|| \&|| \mid \\
|| \&>|| \mid \\
|||\&>|||
\end{gathered}
$$

$0 \& 1$

$0 \& \|$

$0 \&$ III

| \& ||

| \& ||

II \& III

Yes \& No

$1 \& 2$

$1 \& 3$

$2 \& 3$

Yes \& No
Fst (P-value)

$0.01274(0.32422)$

$0.20818(0.07812)$

$-0.02089(0.46582)$

$0.15238(0.17773)$

$0.06714(0.29785)$

-0.03106 (0.99902)

$0.10515(0.19531)$

$0.18605(0.07324)$

$-0.16129(0.76562)$

0.06667 (0.99902)

$0.15152(0.15918)$

$0.12513(0.12891)$

-0.33333 (0.99902)

-0.09091 (0.60938)

-0.08691 (0.72852)

-0.40000 (0.99902)

-0.52941 (0.99902)

$0.13754(0.11523)$

$0.03216(0.24805)$

$0.39683(0.99902)$

0.38444 (0.99902)

-0.45799 (0.91992)

$0.00000(0.39453)$

$-0.01850(0.48242)$

$-0.06950(0.70508)$

$0.00284(0.38184)$

$-0.01720(0.49707)$

0.42177 (0.99902)

$-0.35429(0.80273)$

-0.10092 (0.70703)

-0.17647 (0.99902)

$0.13333(0.31641)$

$-1.00000(0.99902)$

1.00000 (0.99902)

$0.07169(0.18652)$

$-0.41520(0.99902)$

-0.41520 (0.99902)

-0.16049 (0.99902)

-0.16049 (0.99902)

$0.00000(0.99902)$

$0.24883(0.07129)$

$0.17374(0.07520)$

$-0.11892(0.92285)$

$0.20431(0.04785)$

$0.15107(0.06445)$ 
TABLE 5 | Genetic structuring of $\mathrm{GT}_{\mathrm{n}} \mathrm{COL1A2}$ according to epidemiological parameters.

\begin{tabular}{|c|c|c|c|}
\hline $\begin{array}{l}\text { Epidemiological } \\
\text { parameters }\end{array}$ & Source of variation & $\begin{array}{l}\text { Percentage } \\
\text { of variation }\end{array}$ & Fst (P-value) \\
\hline Age & $\begin{array}{l}\text { Within sub-groups } \\
\text { Between sub-groups }\end{array}$ & $\begin{array}{c}96.03862 \\
3.96138\end{array}$ & $0.03961(0.06843)$ \\
\hline Ethnicity & $\begin{array}{l}\text { Within sub-groups } \\
\text { Between sub-groups }\end{array}$ & $\begin{array}{l}91.16560 \\
8.83440\end{array}$ & $0.08834(0.03421)$ \\
\hline Marital status & $\begin{array}{l}\text { Within sub-groups } \\
\text { Between sub-groups }\end{array}$ & $\begin{array}{l}89.42471 \\
10.57529\end{array}$ & $0.10575(0.00782)$ \\
\hline Age at menarche & $\begin{array}{l}\text { Within sub-groups } \\
\text { Between sub-groups }\end{array}$ & $\begin{array}{l}108.72040 \\
-8.72040\end{array}$ & $-0.08720(0.88368)$ \\
\hline $\begin{array}{l}\text { Number of } \\
\text { pregnancies }\end{array}$ & $\begin{array}{l}\text { Within sub-groups } \\
\text { Between sub-groups }\end{array}$ & $\begin{array}{c}95.80665 \\
4.19335\end{array}$ & 0.04193 (0.21994) \\
\hline $\begin{array}{l}\text { Number of } \\
\text { childbirth }\end{array}$ & $\begin{array}{l}\text { Within sub-groups } \\
\text { Between sub-groups }\end{array}$ & $\begin{array}{c}105.40304 \\
-5.40304\end{array}$ & $-0.05403(0.79570)$ \\
\hline $\begin{array}{l}\text { Hormonal } \\
\text { contraception }\end{array}$ & $\begin{array}{l}\text { Within sub-groups } \\
\text { Between sub-groups }\end{array}$ & $\begin{array}{l}75.11658 \\
24.88342\end{array}$ & 0.24883 (0.00098) \\
\hline Diet & $\begin{array}{l}\text { Within sub-groups } \\
\text { Between sub-groups }\end{array}$ & $\begin{array}{c}92.05111 \\
7.94889\end{array}$ & 0.07949 (0.04301) \\
\hline Physical activity & $\begin{array}{l}\text { Within sub-groups } \\
\text { Between sub-groups }\end{array}$ & $\begin{array}{l}84.89311 \\
15.10689\end{array}$ & 0.15107 (0.00684) \\
\hline
\end{tabular}

of a regulatory complex that includes several DNA elements and several trans-activating factors. In humans, COL1A2 contains two microsatellite loci: one located at the 5'-flanking region of the gene is composed of poly CA and poly CG; the other located in the 1st intron is constituted of poly GT. In this study, microsatellite polymorphism $\mathrm{GT}_{\mathrm{n}}$ of intron $1 \mathrm{COL1A2}$ was highlighted in cases of UF in Senegalese women. Based on microsatellite reference pattern that is $(\mathrm{GT})_{14}(\mathrm{CT})(\mathrm{GT})_{3}(\mathrm{CT})(\mathrm{GT})_{3}, 15$ haplotypes were found. These haplotypes indicate a variation in number of GT repeats ranging from 13 to 25 . Of the 15 haplotypes, 12 have the $2284 \mathrm{C}>$ $\mathrm{G}$ mutation and 7 have the $2292 \mathrm{C}>\mathrm{G}$ mutation. Insertions of the dinucleotide $\mathrm{GT}_{\mathrm{n}}$ were found on three haplotypes (microsatellite elongation) compared to eight haplotypes in which they were deletions (microsatellite shortening). This suggests an altered mechanism of the role of COL1A2 gene in UF. Indeed, in a study led by Lei et al. (2005), it has been hypothesized that intron 1 $\mathrm{GT}_{\mathrm{n}}$ polymorphism triggers transcription of gene and variation in number of repeats may be partly responsible for the difference in transcriptional activity. In addition, about 200 different chromosomal abnormalities have been described in UF including long-arm translocations of chromosome 7 occurring in about $17 \%$ of karyotypically abnormal UF (Sandberg, 2005). In contrast to normal tissues where collagen is organized into long, thin, wavy fibrils parallel to the epithelial boundary, collagen fibrils in the tumor stroma are thicker and shorter (Cho et al., 2015). In epithelial ovarian cancer, collagenous pathways perpendicular to the epithelial boundary have been observed (Adur et al., 2014).

Intron 1 of COL1A2 gene exhibits high genetic diversity in UF with $35.34 \%$ polymorphic sites, $95.74 \%$ of which are parsimoniously variable and an average number of nucleotide differences of 10.442, which reflects an important genetic variability. This could be explained by the fact that compared to the myometrium, in UF, not only expression of collagen genes increases (Stewart et al., 1994), but also amount of mature reticulated collagen protein is increased and the more important is modified (Leppert et al., 2004). UF are firm, stiff nodular tumors, a fact understood by all clinicians and confirmed by biomechanical studies (Rogers et al., 2008; Jayes et al., 2013). Extracellular matrix (ECM) proteins, including interstitial collagens, are responsible for this property of "firmness" and mechanical strength of tissues. ECM is a structure that has a supporting role, but on the other hand, it provides signals to cells that determines their behavior. The role of ECM and mechanotransduction as an important signaling factor in human uterus is just beginning to be appreciated. ECM is not just substance surrounding cells, but rigidity compresses cells or stretches them into signals converted into chemical changes, depending on amount of collagen, crosslinking and hydration, as well as other components of ECM. Since connective tissue integrity, architecture, and function result from specific interactions between collagen and other components of ECM, the presence of abnormal collagen chains may have a strong influence on metabolism of non-collagenic components (Tenni et al., 1988). According to study by Hauptman et al. (2018) in colorectal cancers, the results showed that 9 of 16 genes that show differential expression in carcinomas compared to adenomas are components of ECM. Among these components, two collagen type I proteins (COL1A1, COL1A2) are significantly overregulated in cancerous tissues compared to normal tissues. Studies on cell lines suggest that type I collagen adhesion promotes intracellular signaling pathways.

\section{Microsatellite $\mathrm{GT}_{\mathrm{n}}$ Instability in Uterine Fibroids: Correlation With Epidemiological Parameters \\ Ethnicity}

In addition to great variability, repeated dinucleotide $\mathrm{GT}_{\mathrm{n}}$ of intron 1 COL1A2 exhibits heterogeneity given to clinico-pathological parameters in women with UF. Heterogeneity of predisposing factors involved in UF illustrates the complex biological mechanism involved in their development. This suggests the involvement of several molecular mechanisms in occurrence of UF. Prospective studies with larger number of samples would strengthen the correlation observed in the current study. Epidemiological data have mentioned racial disparity in occurrence of UF. Ethnicity has a major influence on development and clinical severity of UF. AfricanAmerican women develop UF at higher frequency and with more severe symptoms. Hispanic women have an intermediate disease profile, and Caucasian women are the least severely affected ethnic group (Velebil et al., 1995; Baird et al., 2003; Wise et al., 2012). It appears that increased incidence and severity of disease in AfricanAmerican women may be due to a combination of specific genetic and environmental factors that are not independent risk factors for the disease (Commandeur et al., 2015). In this study, we took ethnicity into account, although these women are all black. UF are genetically heterogeneous in Bambara, Sérère, Lébou, and Alpulaar and more homogeneous in Diola and Wolof. In a study conducted by Thiaw (2018) on ethnic diversity of Senegalese population (unpublished data), analysis of $\mathrm{GT}_{\mathrm{n}}$ pattern polymorphism shows a genetic differentiation between Diola and Wolof compared to other 
ethnic groups. This differentiation may explain in part $8.83 \%$ of genetic structure of COL1A2 observed in UF by ethnicity.

\section{Marital Status}

Genetic differentiation observed $(10.57 \%)$ is also explained by the differentiation between women according to their marital status; greater differentiation is observed among married and divorced women compared to single. This could be explained by the difference in hormonal status in these women. Studies of Barrett et al. (2015) on ovarian steroid status in marital status showed that estradiol was higher among married women than among unmarried women ( $\beta=0.19,95 \% \mathrm{CI}$ : $0.02-0.36)$ as well as progesterone $(\beta=0.19,95 \% \mathrm{CI}$ : $0.01-0.39)$. In addition, many clinical observations indicate that the development of UF is related to hormonal status (Ross et al., 1986). For example, UF do not occur in prepubertal women and are rarely seen in adolescent girls (Fields and Neinstein, 1996).

\section{Hormonal Contraception}

Our results also indicated that $24.88 \%$ of differentiation observed in cases of UF is explained by a differentiation following hormonal contraception use. Relationship between oral contraceptives and UF has been largely elucidated. But epidemiological data between contraceptive use and UF seems controversial. Published studies show a reduction or absence of risk between oral contraceptives use combined with appearance of UF (Berisavac et al., 2009). One study has shown that oral contraception may play a role in development of UF. Others have found no association between occurrence of UF and use of contraception (Parazzini et al., 1992).

\section{Diet}

In relation to diet, a positive correlation was noted between dietary preference and genetic expression of COL1A2 in UF (7.94\% of genetic differentiation). Genetic differentiation is more observed in patients with meat preference. Recently, Wise and LaughlinTommaso (2016) published results on relationship between dietary fat intake and UF risk in African-American women, confirming an increased risk associated with consumption of omega-3 fatty acids long chain. They validated hypothesis that a diet rich in fruits and vegetables reduced risk. According to studies of Chiaffarino (1999), women with UF consume beef, other red meats, and ham more frequently and have less frequent consumption of green vegetables, fruits, and fish. Multivariate rib ratios were 1.7 for beef and other red meats, 1.3 for ham, and 0.8 for fruit consumption. Limitation of this current diet study is the lack of data on total energy intake because information was collected only on the frequency of vegetable consumption compared to red meat and in interviews with patients. Further research would be interesting to evaluate the effect of fat intake on uterine fibroids biology.

\section{Physical Activity}

There have been few studies on effect of physical activity on risk of developing UF. Nevertheless, our results showed a genetic structuring of UF according to practice or not of sport $(15.10 \%$ of genetic differentiation). Since this is a modifiable factor, more research is needed to evaluate effects of physical activity on UF biology.

\section{CONCLUSION}

Results obtained show, for the first time, a genetic structuring of UF according to ethnicity, marital status, use of contraception, diet, and physical activity, beyond confirming the involvement of COL1A2 gene, in particular dinucleotide length polymorphism $\mathrm{GT}_{\mathrm{n}}$ in occurrence of UF in Senegalese women. In addition to this, results obtained open up avenues for understanding the mechanisms involved in racial variation in the prevalence of UF as well as the predisposing factors. Given the admitted results, it is clear that more research is needed to determine risk factors associated with appearance and growth of UF, as they cause significant morbidity and affect quality of life. A clear overview of the epidemiology of UF has not yet been realized and future research on modifiable risk factors such as vegetarian diet, contraception, physical activity, among others could inform the prevention of myomas and provide new non-surgical approaches to treatment.

\section{ETHICS STATEMENT}

This study was carried out in accordance with the recommendations of World Medical Association's Declaration of Helsinki. The protocol was approved by the Institutional Ethics Committee on Human Research of Cheikh Anta Diop University (Reference: Protocol 0267/2017/CER/UCAD). All subjects gave written informed consent according to a standardized form.

\section{AUTHOR CONTRIBUTIONS}

BK performed molecular analysis, organized the database, performed data analysis, and wrote the first draft of the manuscript. MS contributed to conception and design of the study, revised the manuscript, and read and approved the submitted version.

\section{ACKNOWLEDGMENTS}

We acknowledge the African Center of Excellence for Mother and Child Health (ACE-MCH), Grant number B041715-P00041/2017 and University Cheikh Anta Diop, Dakar, UCAD (http://www.ucad.sn) for technical support. We are most grateful to all Senegalese women who participated in the present study. We are extremely grateful to Dr Daouda CISS Dr Sidy KA and Pr Ahmadou DEM who helped with the collection of samples. Also Pr SEMBENE the head of molecular biology platform of BIOPASS institute of Senegal for all the molecular studies done. 


\section{REFERENCES}

Adur, J., Pelegati, V. B., and De Thomaz, A. A. (2014). Second harmonic generation microscopy as a powerful diagnostic imaging modality for human ovarian cancer. J. Biophotonics. 7, 37-48. doi: 10.1002/jbio.201200108

Akai, J., Kimura, A., and Hata, R. I. (1999). Transcriptional regulation of the human type I collagen a2 (COL1A2) gene by the combination of two dinucleotide repeats. Gene 239, 65-73. doi: 10.1016/S0378-1119(99)00380-7

Audebert, A. (1990). Endométriose externe: histogénèse, étiologie et évolution naturelle. Rev. Praticien. 40, 1077-1081.

Baird, D. D., Dunson, D. B., Hill, M. C., Cousins, D., and Schectman, J. M. (2003). High cumulative incidence of uterine leiomyoma in black and white women: ultrasound evidence. Am. J. Obstet. Gynecol. 188, 100-107. doi: 10.1067/ mob.2003.99

Barrett, E. S., Tran, V., Thurston, S. W., Frydenberg, H., Lipson, S. F., Thune, I., et al. (2015). Women who are married or living as married have higher salivary estradiol and progesterone than unmarried women. Am. J. Hum. Biol. 27 (4), 501-507. doi: 10.1002/ajhb.22676

Berisavac, M., Sparic, R., and Argirovic, R. (2009). Contraception: modern trends and controversies. Srp. Arh. Celok. Lek. 137 (5-6), 310-319. doi: 10.2298/ SARH0906310B

Chiaffarino, F. (1999). Diet and uterine myomas. Obstet. Gynecol. 94 (3), 395-398. doi: 10.1016/S0029-7844(99)00305-1

Cho, A., Howell, V. M., and Colvin, E. K. (2015). The extracellular matrix in epithelial ovarian cancer-a piece of a puzzle. Front. Oncol. 5, 1-16. doi: 10.3389/ fonc. 2015.00245

Commandeur, A. E., Styer, A. K., and Teixeira, J. M. (2015). Epidemiological and genetic clues for molecular mechanisms involved in uterine leiomyoma development and growth. Hum. Reprod. Update. 21 (5), 593-615. doi: 10.1093/ humupd/dmv030

Excoffier, L., and Lischer, H. E. L. (2010). Arlequin suite ver 3.5: a new series of programs to perform population genetics analyses under Linux and Windows. Mol. Ecol. Resources. 10, 564-567. doi: 10.1111/j.1755-0998.2010.02847.x

Fields, K. R., and Neinstein, L. S. (1996). Uterine myomas in adolescents: case reports and a review of the literature. J. Pediatr. Adolesc. Gynecol. 9, 195-198. doi: 10.1016/S1083-3188(96)70030-X

Hall, T. A. (1999). BioEdit: a user-friendly biological sequence alignment editor and analysis program for Windows 95/98/NT. Nucl. Acids. Symp. Ser. 41, 95-98.

Hauptman, N., Boštjancic, E., Zlajpah, M., Rankovic, B., and Zidar, N. (2018). Bioinformatics analysis reveals most prominent gene candidates to distinguish colorectal adenoma from adenocarcinoma. BioMed. Res. Intern. 2018, article 9416515, 10. doi: 10.1155/2018/9416515

Jayes, F. L., Ma, X., Flannery, E. M., Moutos, F. T., Guilak, F., and Leppert P. C. (2013) Biomechanical evaluation of human uterine fibroids after expo-sure to purified clostridial collagenase. In: Supplement to Biology of Reproduction for the 46th Annual Meeting of the Society for the Study of Reproduction; 2013 July 22-26; Montreal, Canada.

Kirkland, S. C. (2009). Type I collagen inhibits differentiation and promotes a stem cell-like phenotype in human colorectal carcinoma cells. BJC. 101 (2), 320-326. doi: 10.1038/sj.bjc.6605143

Krasny, L., Shimony, N., and Tzukert, K. (2010). An in-vitro tumour microenvironment model using adhesion to type I collagen reveals Aktdependent radiation resistance in renal cancer cells. Neph. Dial. Transpl. 25 (2), 373-380. doi: 10.1093/ndt/gfp525

Kumar, S., Stecher, G., and Tamura, K. (2016). Molecular evolution genetics analysis version 7.0 for bigger datasets. Mol. Biol. Evol. 33 (7), 1870-1874.

Lei, S. F., Denga, F. Y., Xiaoa, S. M., Chena, X. D., and Deng, H. W. (2005). Association and haplotype analyses of the COL1A2 and ER-a gene polymorphisms with bone size and height in Chinese. Bone 36, 533-541. doi: 10.1016/j.bone.2004.11.002

Leppert, P. C., Baginski, T., Prupas, C., Catherino, W. H., Pletcher, S., and Segars, J. H. (2004). Comparative ultrastructure of collagen fibrils in uterine leiomyomas and normal myometrium. Fertil. Steril. 82 (3), 1182-1187. doi: 10.1016/j. fertnstert.2004.04.030

Librado, P., and Rozas, J. (2009). Dna SP v5: A software for comprehensive analysis of DNA polymrphism data. Bioinformatics 25, 1451-1452.

Parazzini, F., Negri, E., La Vecchia, C., Fedele, L., Rabaiotti, M., and Luchini, L. (1992). Oral contraceptive use and risk of uterine fibroids. Obstet. Gynecol. 79, 430-433. doi: 10.1097/00006250-199203000-00021

Rogers, R., Norian, J., Malik, M., Abu-Asab, M., Christman, G., Malik, M., et al., et al. (2008). Mechanical homeostasis is altered in uterine leiomyoma. Am. J. Obstet. Gynecol. 198 (4), 1-474. doi: 10.1016/j.ajog.2007.11.057

Ross, R. K., Pike, M. C., Vessey, M. P., Bull, D., Yeates, D., and Casagrande, J. T. (1986). Risk factors for uterine fibroids: reduced risk associated with oral contraceptives. Br. Med. J. 293, 359-362. doi: 10.1136/bmj.293.6543.359

Rossert, J., Terraz, C., and Dupont, S. (2000). Regulation of type I collagen genes expression. Nephrol. Dial. Transplant. 15, 66-68. doi: 10.1093/ndt/15. suppl_6.66

Sandberg, A. A. (2005). Updates on the cytogenetics and molecular genetics of bone and soft tissue tumors: leiomyoma. Cancer Genet. Cytogenet. 158, 1-26. doi: 10.1016/j.cancergencyto.2004.08.025

Stewart, E. A., Friedman, A. J., Peck, K., and Nowak, R. A. (1994). Relative overexpression of collagen type I and collagen type III messenger ribonucleic acids by uterine leiomyomas during the proliferative phase of the menstrual cycle. J. Clin. Endocrin. Metabol. 79 (3), 900-906. doi: 10.1210/ jcem.79.3.8077380

Tenni, R., Cetta, G., Dyne, K., Rossi, A., Quacci, D., Lenzi, L., et al. (1988). Type I procollagen in the severe non-lethal form of osteogenesis imperfecta. Defective pro-a1(I) chains in a patient with abnormal proteoglycan metabolism and mineral deposits in the dermis. Hum. Genet. 79, 245-250. doi: 10.1007/ BF00366245

Thiaw, M. (2018). Diversité génétique de la population Sénégalaise: comparaison entre groupes ethniques. Mémoire de Diplôme de Master en Biologie Animale (mémoire non publié). Dakar, Sénégal: Faculté des Sciences et Techniques, Université Cheikh Anta Diop.

Thompson, J. D., Higgins, D. G., and Gibson, T. J. (1994). CLUSTAL W: improving the sensitivity of progressive multiple sequence alignment through sequence weighting, position specific gap penalties and weight matrix choice. Nucl. Acids Res. 22 (22), 4673-4680. doi: 10.1093/nar/22.22.4673

Trojonowska, M. (2002). Molecular aspects of scleroderma. Front. Biosci. 7, 608 618. doi: 10.2741/A798

Yasul, W., Oue, N., and Ito, R. (2004). Search for new biomarkers of gastric cancer through serial analysis of gene expression and its clinical implications. Cancer Sci. 95, 385-392. doi: 10.1111/j.1349-7006.2004.tb03220.x

Velebil, P., Wingo, P. A., Xia, Z., Wilcox, L. S., and Peterson, H. B. (1995) Rate of hospitalization for gynecologic disorders among reproductiveage women in the United States. Obstet. Gynecol. 86, 764-769. doi: 10.1016/0029-7844(95)00252-M

Wise, L. A., and Laughlin-Tommaso, S. K. (2016). Epidemiology of uterine fibroids from menarche to menopause. Clin. Obstet. Gynecol. 59 (1), 2-24. doi: 10.1097/ GRF.0000000000000164

Wise, L. A., Ruiz-Narvaez, E. A., Palmer, J. R., Cozier, Y. C., Tandon, A., Patterson, N., et al. (2012). African ancestry and genetic risk for uterine leiomyomata. Am. J. Epidemiol. 176, 1159-1168. doi: 10.1093/aje/kws276

Conflict of Interest Statement: The authors declare that the research was conducted in the absence of any commercial or financial relationships that could be construed as a potential conflict of interest.

Copyright (c) 2019 Kénémé and Sembène. This is an open-access article distributed under the terms of the Creative Commons Attribution License (CC BY). The use, distribution or reproduction in other forums is permitted, provided the original author(s) and the copyright owner(s) are credited and that the original publication in this journal is cited, in accordance with accepted academic practice. No use, distribution or reproduction is permitted which does not comply with these terms. 